\title{
The Use of Innovative Pedagogical Technologies for Automation of the Specialists' Professional Training
}

\author{
Alla V. Diachenko ${ }^{1}$, Boris P. Morgunov ${ }^{2}$, Tetiana P. Melnyk ${ }^{3}$, Olena I. Kravchenko ${ }^{4} \&$ Ludmila V. Zubchenko $^{5}$ \\ ${ }^{1}$ Department of Industrial Design and Computer Technologies, Faculty "Design", Kyiv State Academy of Decorative \\ Arts and Design named after Mykhailo Boychuk, Kyiv, Ukraine \\ ${ }^{2}$ Film and Television Directing Faculty, GITR Film \& Television School, Moscow, Russian Federation \\ ${ }^{3}$ Department of the Ukrainian Language, I. Horbachevsky Ternopil National Medical University of the Ukrainian \\ Ministry of Public Health, Ternopil, Ukraine \\ ${ }^{4}$ Department of Public Service and Management of Educational and Social Institutions, Educational and Research \\ Institute of Public management, Administration and Postgraduate education, Luhansk Taras Shevchenko National \\ University, Starobilsk, Ukraine \\ ${ }^{5}$ Department of Combat and Special Physical Training, Donetsk Law Institute of the Ministry of Internal Affairs of \\ Ukraine (Kryvyi Rih), Kryvyi Rih, Ukraine \\ Correspondence: Olena I. Kravchenko, Department of Public Service and Management of Educational and Social \\ Institutions, Educational and Research Institute of Public management, Administration and Postgraduate education, \\ Luhansk Taras Shevchenko National University, Starobilsk, Ukraine. E-mail: docteurdeluniversite@yahoo.com
}

Received: November 27, 2019

Accepted: December 12, 2019

Online Published: December 14, 2019

doi:10.5430/ijhe.v8n6p288

URL: https://doi.org/10.5430/ijhe.v8n6p288

\begin{abstract}
The purpose of this study was to find out how students and teachers perceive the automation of the specialists' professional training process and the impact factors of perceiving the learning activity of such kind by students and faculty. The experimental model of automated learning was based on an express course in the academic subjects "Roman Private Law" and "Latin (Latin Law Phraseology)". The following methods were used to analyze the quantitative data: Chi-Square statistical method and triangulation. STATA Software was used to process the data. An online Text Analyzer utility was used to process the answers of the focus group respondents to determine the research categories. Automation of the professional training process has a positive impact on education and greatly enhances the opportunities for both teachers and students making it possible to effectively solve the key task of higher education - to teach the student an autonomous learning, as it forms the skills of managing their own time, self-organization, self-motivation, and reflection. Automation of the professional training process through the use of innovative pedagogical technologies brings about a number of new opportunities and advantages, such as: prominence (detailed elaboration of professional processes with different levels), interactivity (ability to control and influence the process), focusing (allows to remove distracting factors, to concentrate on the material). In the proposed automated model, Chatbot can be programmed so that the course participant will not feel the difference between the language of the real person and the machine. Queries that cannot be processed by Chatbot are answered by the course administrator/moderator via email. This model can be adapted and upgraded to teach other professionally oriented theoretical and applied courses. In addition, Chatbot can be used by higher education institutions in managing a university admissions process to provide applicants with information about admission requirements, programmes, specialties, etc.
\end{abstract}

Keywords: pedagogical technologies, training automation, higher education institutions, chatbots

\section{Introduction}

The idea of utilizing the innovative pedagogical technologies (information technologies) to automate the educational process, and professional training in particular, is increasing in number of supporters worldwide (Vetchanin, 2018; Kinson, 2018a; 2018b; Ostdick, 2016; Patrinos, Kattan, \& MacDonald, 2017; Scandura, 2010). This trend is associated not only with the introduction of an alternative learning environment that simplifies, diversifies, engages a larger audience, eliminates the factor of subjectivity of the teacher in evaluating the learning outcomes and increases the effectiveness of the educational process, but also with the focus of educational policy on improving the 
accessibility of education, on optimizing state funding (the Ukrainian scenario of maintaining state-owned educational establishments) and consumers of educational services. Optimism is replenished by analytic forecasts, which predict that in 2025 the number of e-learning students will exceed 3.5 times the number of those enrolled in the traditional form of education and will reach 650 million (as compared to 17.5 million in 2018) (Bataev, 2015). The examples of attempting to automate the education process are the Intelligent Tutoring Systems (Nwana, 1990; Mousavinasab et al., 2018) and the use of Chatbots (Singh, 2018). The above has inspired us to research students' and teachers' perceptions of the automated learning process.

\subsection{Literature Review}

Intelligent Tutoring Systems (in some sources, "Knowledge-Based Tutoring System" (KBTS) or "Adaptive Tutoring System" (ATS) (Streitz, 1988) is a computer system designed to promptly ensure a student's request to individualized learning or feedback, without the intervention of an instructor (teacher)-person (Sedlmeier, 2001). Such a system uses artificial intelligence that has been programmed to use a particular knowledge base, taking into account the student's knowledge database and accessibility to the use of certain pedagogical tools for the implementation of educational tasks. Among the advantages of intelligent tutoring systems the following can be mentioned: reduced dependence on human resources (human factor); improving students' academic performance by using a two-step learning approach: first, to find out what the students know, and then to answer the relevant questions; typically higher student test scores than the traditional system; providing immediate comments on "yes/no" answers; personalized task selection; query prompts and use of learning incentives; 24/7 access (Briggs, 2014).

Chatbots in learning (Chatbots) or AI-driven conversation tools are used in the educational environment as game changers to enhance students' engagement and collaboration (Goda et al., 2014). They can simulate standardized chat conversation by using a series of messages that will look like an online interactive lecture to students. After such training, the chatbot will ask the student to take a quiz, which they can either send to the teacher or the course administrator for review or immediately receive the answers to questions or assignments. In such a way, teachers can also easily track the students' performance. It is proved that the chatbot is better able to cope with the task of engaging students to study the academic subject. This is related to the students' habit of emailing on instant messaging platforms and social media. Moreover, Hubert the chatbot, for example, can conduct student surveys on how to improve the course, what needs to be changed, what works well and what doesn't. Then the chatbot analyzes the answers, identifies the keywords mentioned by most students, and sends them to the teacher. Chatbots can track student searches, and this information can be used to update the course content (Singh, 2018; Farkash, 2018).

\subsection{Problem Statement}

In view of the above, the research into the problem of using innovative pedagogical technologies to automate the specialists' vocational training process can be considered a relevant objective of pedagogical research. As Judith Donath predicts (in Anderson \& Rainie, 2018), by the year 2030 bots (intelligent-seeming programs that interact with us in human-like ways) will facilitate the greatest proportion of social situations including education which might result in greater students' academic achivements and higher learning motivation.

This quantitative research is appropriate to resolve the above specific problem (automation of the vocational training process) and is a contribution to the study of automation of the learning process of specialists' vocational training through the use of innovative AI-based pedagogical technologies within the settings of tertiary school.

\section{Research questions}

Therefore, this study aimed to identify: 1) how students and teachers perceive the automation of the specialists' professional training process; 2) impact factors of perceiving such training activity in a positive or negative way.

\section{Research Methodology}

The study had a three-stage quantitative research design, which utilized the general scientific theoretical, empirical, and statistical methods. With the aim of diagnosing the homogeneity of the groups, a psychometric test and the methods of T. I. Ilyina's "The research into the learning motivation at HEI" (Department of Theory and Methods of Physical Education, n./d.) were used, as well as the questionnaires to identify the perception and perception factors of the specialists' professional training automation.

\subsection{Research Design}

Two academic subjects were chosen for the experimental testing of the study automated model, namely: "Roman Private Law" and "Latin (Latin Law Phraseology)". These subjects were selected by interviewing 765 students of specialty 081 "Law", the first (bachelor) level of specialization "Jurisprudence" and 23 teachers of three institutions 
of higher education (State Higher Education Institution "Kyiv National Economic University named after Vadym Hetman" (Law School), Yuriy Fedkovych Chernivtsi National University, Yaroslav the Wise National Law Academy of Ukraine, which aimed to identify the least priority subject in view of providing by them the key learning outputs. The automated model of educational activity included such components as follows: notification of students through the system of automated mailings (the automated mail service Mailigen) + automated mailing service MailChimp; formation of the students' a database, their registration and involvement in educational activities; chatbot's support (written and audio) of the students' educational performance (the platform for generic process automation GetResponce) + website designer WordPress + InteliWISE AI-Chatbot; as well as providing chatbot's feedback on student performance results (InteliWISE AI-Chatbot). The chart of the study can be presented graphically as follows (Fig. 1).

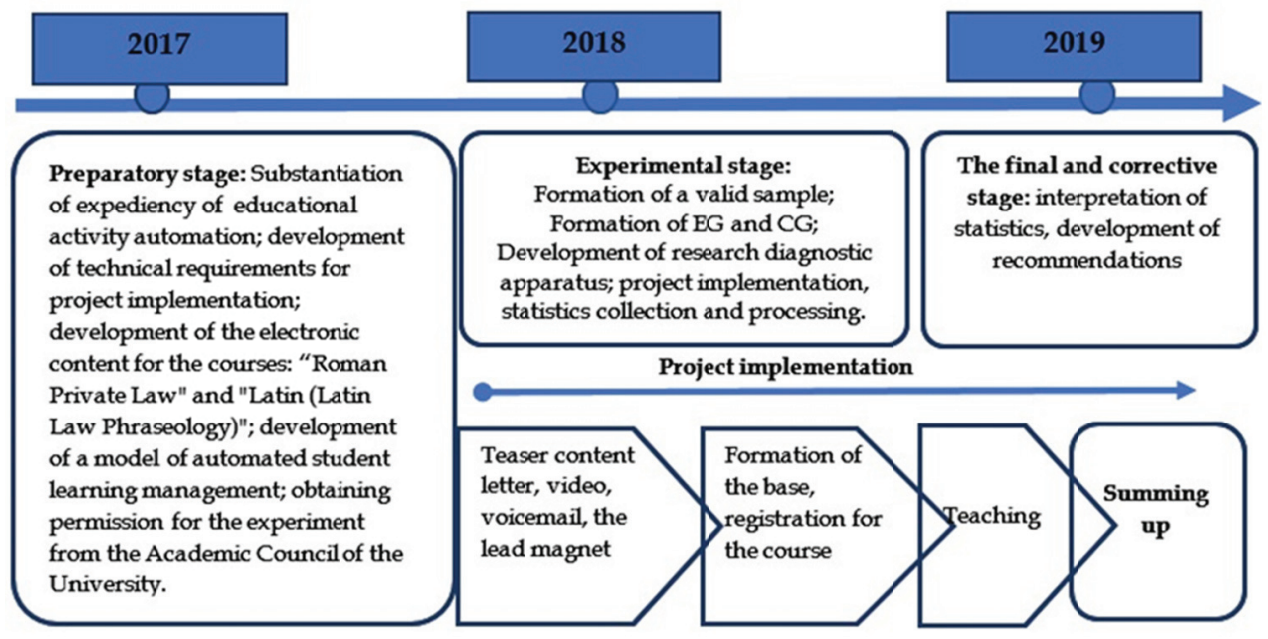

Figure 1. The flow/timeline of the study

2.1.1 The Description of the Content and Structure of the Automated Express Course on the Academic Subject "Roman Private Law"

The course was based on 10 case studies and corresponded to the content of the module "The property right" in accordance with the program of the specified academic subject. The cases were arranged in the order of difficulty: from simple to complex ones, and aimed to create game situations with the transition of the activity to a higher level. Each session (case) corresponded to a unified structure, namely: 1) Chatbot (by voice messages) presents a case (for example, Case 1. "A stranded labeled sheep wandered into an alien flock and grazed on an alien meadow all summer. Eventually it was found by the owner. Does he have the right to throw a rope at her and take her away despite the owner's protest? Does it matter that the possession of the sheep was a compulsive and open (not secret) action? Can the counterclaim for damages related to the feeding of the sheep, its protection, etc. be taken into account?"; 2) Chatbot consequtively offers the student 5 (five) answer options that the student must agree or disagree with. Chatbot comments on the correctness of the student's answers in an encouraging manner; 3) Chatbot suggests the student reading theoretical material on the subject (or watching an educational video) and recording a short video in which he/she explains and comments on the case. The CRM system sends the video to other two course participants for them to rate it by checklist; 4) Chatbot notifies the student of the need to do a quick quiz to evaluate the material studied. 5) Upon the completion of the quiz, Chatbot comments on the results, awards the prize (if the result is higher than $80 \%$ of the scores), and advises the student (in an encouraging manner) on further learning and upward transition.

2.1.2 Description of the Content and Structure of the Automated Express Course in the academic subject "Latin (Latin Law Phraseology)"

The course consisted of 10 classes, that had been designed in accordance with the program of the specified academic subject. Each lesson was built on a unified structure, namely: 1) Chatbot (by voice messages) presents new lexical units $(8-12)$ and offers to match them with the pictures; Chatbot comments on the student's attempts in an encouraging manner; 2) Chatbot invites the student to do a shortread (70-100 printed characters) and give "YES/NO" answers to the questions; Chatbot comments on the student's attempts in an encouraging manner and explains the mistakes; 3) Chatbot invites the student to familiarize themselves with the grammatical material and to perform a 
grammar test; Upon completion, the course participant is provided with the correct answers accompanied with comments; 4) The lesson ends with a short quiz, which includes the tasks of comprehension check of the lexical units, reading comprehension and grammar structures' use; 5) Upon completion of the test, Chatbot comments on the results, awards the prize (if the result is higher than $80 \%$ of the scores), and advises the student (in an encouraging manner) on further learning and upward transition.

\subsection{Sample Formation}

At the empirical stage, 765 second-year students of the specialty 081 "Law", the first level (bachelor) level of specialization " Jurisprudence" and and 23 teachers of three institutions of higher education (State Higher Education Institution "Kyiv National Economic University named after Vadym Hetman" (Law School), Yuriy Fedkovych Chernivtsi National University, Yaroslav the Wise National Law Academy of Ukraine. An online valid sample calculator was used to determine the size of the representative sample. For the specified overall population $=788$ persons (confidence interval 14,95\%, confidence probability 95\%), the required sample size was 46 . The formation of the experimental group (EG) and control group (CG) was done taking into account the abovementioned number. The experimental group (EG) counted 23 persons (12 female 18-19-year-olds and 11 male 18-19-year-olds) and the control group (CG) counted the same - 23 persons (10 female 18-19-year-olds and 13 male 18-19-year-olds). To determine the groups' homogeneity, such averages were used as students' academic performance (AP), psychometric test (PT) and T.I. Ilyina's method "The research into the learning motivation at HEI" (LM) (Department of Theory and Methods of Physical Education, n./d.). The values were translated into a five-point scale. The results of determining the groups' homogeneity according to these indicators are summarized (see Table 1).

Table 1. Averages of students' academic performance (AP), psychometric test (PT) scores and T. I. Ilyina's method (LM) evaluated on a five-point scale

\begin{tabular}{ccccc}
\hline Groups & $n$ & $A P$ & $P T$ & $L M$ \\
\hline CG & 23 & 3.8 & 3.8 & 3.2 \\
EG & 23 & 3.7 & 3.6 & 3.4
\end{tabular}

As can be seen in Table 1, the averages of academic performance, psychometric test, and learning motivation are about the same across all the indicators, suggesting that the groups are homogeneous and can be involved in the research.

\subsubsection{Tools for Collecting and Processing Statistics}

Quantitative methods were used to address the research questions, such as test results performed by students from both groups; questionnaires for students and teachers to determine how students and teachers perceive the automation of the training process; focus group survey to determine the impact factors of the study organization model. The following were used to analyze the quantitative data: Chi-Square statistical method and triangulation (Ali, $\&$ Bhaskar, 2016). STATA Software (Stata, n./d.) was used to process the research data.

An online Text Analyzer utility was used to process the responses of the focus group respondents to determine the research categories. The focus group included 9 students and 2 teachers (experts). The questionnaire consisted of 5 questions:

1) Describe your impressions of (participating in) an automated professional course.

2) What specifically influenced your positive (negative) perception?

3) Was the course useful for your professional development (for the student's professional growth)? What was the course specifically beneficial in?

4) Would you recommend an automated course to your friends (acquaintances)? Why would you?

5) Would you pay your own money to take such a course? How much would you spend on it? Why?

In the course of the answers' processing, the usage frequency of such keywords as "changes", "better", "convenience", "benefit" was being monitored. Overall, the focus group participants' responses were processed using the focus group research recommendations (OMNI, n./d.; Krueger \& Casey, 2000; Onwuegbuzie, Dickinson \& Leech, 2009).

\section{Results}

The experiment resulted in positive developments in students' academic performance in the subjects of Roman Private Law and Latin (Latin Law Phraseology), and the dynamics of students' learning motivation (see Table 2). 
Table 2. Averages of students' academic performance (AP) scores and T. I. Ilyina's method (LM) evaluated on a five-point scale

\begin{tabular}{cccccc}
\hline & & \multicolumn{2}{c}{ Before the experiment } & \multicolumn{2}{c}{ After the experiment } \\
\hline Groups & $n$ & $A P$ & $L M$ & $A P$ & AP \\
CG & 23 & 3.8 & 3.2 & 3.9 & 3.3 \\
EG & 23 & 3.7 & 3.4 & 4.2 & 3.9 \\
\hline
\end{tabular}

As can be seen from Table 2, in the indicators of the experimental group students, positive changes in academic performance (AP) and learning motivation (LM) are more significant (by 17\%) than in the control group (by 4\%), which allows to claim the effectiveness of the automated model for the implementation of specialists' professional training.

In addition, the indirect result was the increase in students' attendance in academic subjects that use computer and smart technologies in their learning.

Among the impact factors of perceiving such a learning activity - positively or negatively - in the process of interviewing the focus group respondents were the following: usefulness for professional growth, format convenience, possibility of multiple reviewing of the lesson, varied and convenient pedagogical (educational) tools, Chatbot helps in coping with the lack of face-to-face contact with the teacher.

Using the Chi-Square statistical method, we distributed the impact factors by weight for the implementation of an automated model. These are as follows: results of students' academic performance; results of diagnostic tests and techniques; the amount of time spent on studying according to an experimental model; attendance (Table 3).

Table 3. Distribution of impact factors by weight for implementing the automated model

\begin{tabular}{|c|c|c|c|c|c|c|c|c|}
\hline No. & Impact factors & 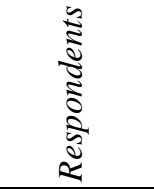 & 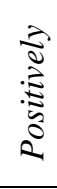 & $\begin{array}{l}\vec{a} \\
\vec{\Xi} \\
\dot{\Xi} \\
\infty \\
\sum^{\infty}\end{array}$ & 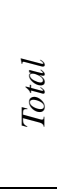 & $x ?$ & 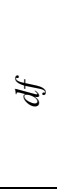 & 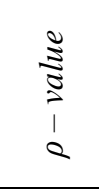 \\
\hline \multirow[t]{2}{*}{1.} & \multirow[t]{2}{*}{ Usefulness for professional growth } & Students & 9 & 0 & \multirow{2}{*}{11} & \multirow{2}{*}{3.234} & \multirow{2}{*}{1} & \multirow{2}{*}{0.433} \\
\hline & & Teachers & 2 & 0 & & & & \\
\hline \multirow[t]{2}{*}{2.} & \multirow[t]{2}{*}{ Format convenience } & Students & 9 & 0 & \multirow{2}{*}{11} & \multirow{2}{*}{3.212} & \multirow{2}{*}{2} & \multirow{2}{*}{0.417} \\
\hline & & Teachers & 1 & 1 & & & & \\
\hline \multirow[t]{2}{*}{3.} & \multirow{2}{*}{$\begin{array}{c}\text { Possibility of the lesson's repeatable } \\
\text { viewing }\end{array}$} & Students & 8 & 1 & \multirow{2}{*}{11} & \multirow{2}{*}{2.921} & \multirow{2}{*}{2} & \multirow{2}{*}{0.567} \\
\hline & & Teachers & 2 & 0 & & & & \\
\hline \multirow[t]{2}{*}{4.} & \multirow{2}{*}{$\begin{array}{l}\text { Varied and convenient pedagogical } \\
\text { (educational) tools }\end{array}$} & Students & 7 & 2 & \multirow{2}{*}{11} & \multirow{2}{*}{2.899} & \multirow{2}{*}{1} & \multirow{2}{*}{0.454} \\
\hline & & Teachers & 2 & 0 & & & & \\
\hline \multirow[t]{2}{*}{5.} & \multirow{2}{*}{$\begin{array}{l}\text { Chatbot helps to overcome the lack of } \\
\text { personal contact with the teacher }\end{array}$} & Students & 9 & 0 & \multirow{2}{*}{11} & \multirow{2}{*}{3.332} & \multirow{2}{*}{1} & \multirow{2}{*}{0.397} \\
\hline & & Teachers & 2 & 0 & & & & \\
\hline
\end{tabular}

$n=11 ; a \leq 0.05$.

So, as we see the values indicate that these variables (impact factors) are dependent on each other and that there is an essential relationship between them.

\subsection{The Results of Processing the Responses of the Focus Group Respondents}

1) Describe your impressions of (participating in) the automated professional course. The overwhelming majority of the respondents favored an automated professional course. Nine students and 2 teachers indicated that this model is useful for the students' professional growth. Two teachers agreed that such a system diversifies pedagogical (teaching) tools. Eleven respondents agreed that Chatbot helps to overcome the lack of personal contact with the teacher.

2) What specifically influenced your positive (negative) perception? As for the factors that influenced positive perception, 7 respondents identified "convenience", "diversity", "efficiency", "educational and professional value". Among the negative factors, 4 respondents indicated "having the relevant computer skills", "technical problems". 
3) Was the course useful for your professional development (for the student's professional growth)? What was the course specifically benefecial in? Eleven respondents agreed that the automated learning model is viable and useful for training due to its adaptability and affordability.

4) Would you recommend an automated course to your friends (acquaintances)? Why would you? Six students and 1 teacher positively answered this question. Their key arguments were "the lack of teacher's subjectivity in the process" and "the lack of over-theorizing of the content."

5) Would you pay your own money to take such a course? How much would you spend on it? Why? While 8 students answered the question in the positive, 2 teachers refrained from answering. As for the price, the suggested amount was \$10-25 per course. The reason was the market value of such courses available from the resource like Udemy.

\subsection{Limitations of the Study}

The major limitations of this study are as follows: the participation of only one of higher educational institution, specialization of students, number of automated modules, age of students. The other constraint is the bias of the study organizers, as they shared a common goal - the positive results of the experiment.

\section{Discussion}

This study tested and proved feasibility of the learning environment based on AI information technology which was supposed to substitute the instructor in the course delivery and management. Additionally, it was discovered that automated learning model is capable to reformat the vocational training, increase its efficiency, positively impact on students' learning motivation and their learning outcomes.

Furthermore, the use of technology in itself has not only helped to acquire the necessary training material, but also to develop skills in working with these technologies, resulting in an enhanced computer literacy. The results make it possible to conclude that the automated (computerized) course significantly expands the pedagogical possibilities of presenting educational material, not only in a rational but also in a figurative form through the use of color, sound, graphics, infographics, animation, all kinds of video content. In addition, Chatbot, which we integrated into the automated course, constantly involved students in the learning process, provided interactivity of forms of learning, the ability to simulate student-teacher dialogue, leveled conflict between them, and has fundamentally changed the ways of managing students' learning activities.

The research has enhanced previous research on the issue of (a) designing intelligent tutoring systems (Intelligent Tutoring Systems) (Dermeval et al., 2018), (b) automation of educational support (Rockwell Automation, 2012), (c) Chatbot use in the educational process (Hajare et al., 2018; Singh, 2018); d) the use of smart technologies in training (Victoria State Government, 2010).

The results of the study suggest that the automation of the training process is a complex technical task, with promising long-term implications.

Overall, the study verified that students and faculty are positive about the automation of the professional training process and acknowledge its effectiveness.

\section{Conclusions and Recommendations for Future Research}

Automation of the professional training process has a positive impact on the education and significantly broadens the possibilities of both teachers and students and allows to effectively address the key objective of higher education - to teach the student an autonomous learning, as it forms the skills of time management, self-organization, self-motivation, and reflection.

Automation of the professional training process through the use of innovative pedagogical technologies opens up a number of new opportunities and benefits, such as: prominence (detailed elaboration of professional processes with different levels), interactivity (ability to control and influence the process), focusing (allows to remove distracting factors, to concentrate on the material). In the proposed automated model, Chatbot can be programmed so that the course participant will not feel the difference between the language of the real person and the machine. Queries that cannot be processed by Chatbot are answered by the course administrator via email. This model can be adapted and upgraded to teach other professionally oriented theoretical and applied courses. In addition, Chatbot can be used by higher education institutions in managing a university admissions process to provide applicants with information about admission requirements, programs, specialties, etc. 


\section{References}

Anderson, J. \& Rainie, L. (2018). Artificial Intelligence and the Future of Humans. Pew Research Center. Retrived https://www.pewresearch.org/internet/2018/12/10/artificial-intelligence-and-the-future-of-humans/

Bataev, A. V. (2015). Analysis of the global distance education market. Young Scientist, 20, 205-208.

Vetchanin, Ye. (2018). Current state of computerization of education. Educological discourse, 1-2(20-21). 341-352.

Department of Theory and Methods of Physical Education. (n./d.). T. I. Ilyina's method "The research into the learning motivation at HEI". Retrieved http://fizkultura.kpnu.edu.ua/wp-content/uploads/sites/13/2014/01/\%D0\%9C\%D0\%B5\%D1\%82\%D0\%BE\%D0 $\% \mathrm{~B} 4 \% \mathrm{D} 0 \% \mathrm{~B} 8 \% \mathrm{D} 0 \% \mathrm{BA} \% \mathrm{D} 0 \% \mathrm{~B} 0-\% \mathrm{C} 2 \% \mathrm{AB} \% \mathrm{D} 0 \% 92 \% \mathrm{D} 0 \% \mathrm{~B} 8 \% \mathrm{D} 0 \% \mathrm{~B} 2 \% \mathrm{D} 1 \% 87 \% \mathrm{D} 0 \% \mathrm{~B} 5 \% \mathrm{D} 0 \% \mathrm{BD} \% \mathrm{D}$ 0\%BD\%D1\%8F-\%D0\%BC\%D0\%BE\%D1\%82\%D0\%B8\%D0\%B2\%D0\%B0\%D1\%86\%D1\%96\%D1\%97-\%D 0\%BD\%D0\%B0\%D0\%B2\%D1\%87\%D0\%B0\%D0\%BD\%D0\%BD\%D1\%8F-\%D1\%83-\%D0\%B2\%D0\%B8\% D1\%88\%D1\%96\%C2\%BB-\%D0\%A2.\%D0\%86.-\%D0\%86\%D0\%BB\%D1\%8C\%D1\%97\%D0\%BD\%D0\%B0. pdf

Ali, Z. \& Bhaskar, S. B. (2016). Basic statistical tools in research and data analysis. Indian Journal of Anaesthesia, 60(9), 662-669.

Briggs, S. (2014). Intelligent Tutoring Systems - Can They Work for You? informED. Retrieved https://www.opencolleges.edu.au/informed/other/intelligent-tutoring-systems/

Dermeval, D., Paiva, R., Bittencourt, I., Vassileva, J. \& Ferreira da Silva, D. (2018). Authoring Tools for Designing Intelligent Tutoring Systems: a Systematic Review of the Literature. International Journal of Artificial Intelligence in Education, 28(3), 336-384.

Farkash, Z. (2018). Higher Education Chatbot: Chatbots Are the Future of Higher Education. Chatbots Life. Retrieved https://chatbotslife.com/higher-education-chatbot-chatbots-are-the-future-of-higher-education-51f151e93b02

Goda, Y., Yamada, M., Matsukawa, H., Hata, K. \& Yasunami, S. (2014). Conversation with a Chatbot before an Online EFL Group Discussion and the Effects on Critical Thinking. The Journal of Information and Systems in Education, 13(1), 1-7. https://doi.org/10.12937/ejsise.13.1

Hajare, A., Bhosale, P., Nanaware, R. \& Hiremath, G. (2018). Chatbot for Education System. International Journal of Computer Science, 3(2), 52-57.

Kinson, N. (2018a). How automation will impact education. BetaNews. Retrieved https://betanews.com/2018/10/24/how-automation-will-impact-education/

Kinson, N. (2018b). Is there a place for automation in education? EdTechnology. Retrieved https://edtechnology.co.uk/Article/is-there-a-place-for-automation-in-education/

Krueger, R. A. \& Casey, M. A. (2000). Focus groups: A practical guide for applied researchers (3rd ed.). Thousand Oaks, CA: Sage.

Mousavinasab, E., Zarifsanaiey, N., Kalhori, S. R. N., Rakhshan, M., Keikha L. \& Saeedi, M. G. (2018). Intelligent tutoring systems: a systematic review of characteristics, applications, and evaluation methods. Interactive Learning Environments.

Nwana, H. S. (1990). Intelligent tutoring systems: an overview. Artificial Intelligence Review, 4(4), 251-277. https://doi.org/10.1007/BF00168958

Scandura, J. M. (2010). The Role of Automation in Instruction. Polibits, 42, 21-42.

Onwuegbuzie, A. J., Dickinson, W. B. \& Leech, N. L. (2009). A Qualitative Framework for Collecting and Analyzing Data in Focus Group Research. International Journal of Qualitative Methods, 8(3), 1-21. https://doi.org/10.1177/160940690900800301

Ostdick, N. (2016). Teach Me: Automation's Role in Education. UiPath. Retrieved https://www.uipath.com/blog/teach-me-automations-role-in-education

Patrinos, H. A., Kattan, R. B. \& MacDonald, K. (2017). The implications of automation for education. World Bank Blogs. Retrieved http://blogs.worldbank.org/education/implications-automation-education

Rockwell Automation. (2012). Rockwell Automation Educational Support Program: Classroom Toolkit \& Support 
User

Guide.

Retrieved https://www.reynoldsonline.com/ASSETS/DOCUMENTS/ITEMS/EN/ALBR9324RL0LDRENE_Spec.pdf

Singh, R. (2018). AI and Chatbots in Education: What Does the Future Hold? Chatbot Magazine. Retrieved https://chatbotsmagazine.com/ai-and-chatbots-in-education-what-does-the-futurehold-9772f5c13960

Sedlmeier, P. (2001). Intelligent Tutoring Systems. in N. J. Smelser \& P. B. Baltes (Eds.), International Encyclopedia of the Social \& Behavioral Sciences (pp. 7674-7678), Oxford: Pergamon.

Streitz, N. A. (1988). Mental Models and Metaphors: Implications for the Design of Adaptive User-System Interfaces. In H. Mandl \& A. Lesgold (Eds.), Learning Issues for Intelligent Tutoring Systems, (pp. 164-186). New York: Springer.

Stata. (n./d.). STATA Software. Retrieved https://www.stata.com/

OMNI. (n./d.). Toolkit for Conducting Focus Groups. Retrieved https://www.nyla.org/max/userfiles/Documents/D._Focus_Group_Toolkit.pdf

Victoria State Government. (2010). What is smart technology for the smart classroom? Retrieved https://www.education.vic.gov.au/Documents/about/news/archive/7ensmarttech.pdf 